\title{
L'éducation du « sujet » au cœur de la cité globale
}

\section{Christine Delory-Momberger}

\section{(2) OpenEdition}

Journals

Édition électronique

URL : http://journals.openedition.org/trema/3078

DOI : 10.4000/trema.3078

ISSN : 2107-0997

\section{Éditeur}

Faculté d'Éducation de l'université de Montpellier

\section{Édition imprimée}

Date de publication : 1 décembre 2013

Pagination : $90-101$

ISSN : 1167-315X

\section{Référence électronique}

Christine Delory-Momberger, « L'éducation du « sujet » au cœur de la cité globale », Tréma [En ligne],

40 | 2013, mis en ligne le 01 décembre 2015, consulté le 10 décembre 2020. URL : http://

journals.openedition.org/trema/3078; DOI : https://doi.org/10.4000/trema.3078

Ce document a été généré automatiquement le 10 décembre 2020.

Trema 


\title{
L'éducation du "sujet » au cour de la cité globale
}

\author{
Christine Delory-Momberger
}

1 La difficulté particulière de l'école française à répondre à la diversité individuelle et collective des enfants et des adolescents qu'elle accueille ne peut être comprise que si on la replace dans l'histoire moderne de l'institution scolaire en France, en la comparant avec les traditions des autres systèmes éducatifs. «L'école de la nation» et «l'école du savoir ", qui définissent l'École de la République, postulent un modèle à la fois communautaire et universaliste qui est de plus en plus souvent mis en échec dans l'école française actuelle, lorsque celle-ci est directement confrontée à la pluralité, la diversité, l'hétérogénéité de la population scolaire, et consécutivement aux disparités sociales et culturelles et aux inégalités qu'elles produisent.

2 Sur ce fonds historique et idéologique, on se propose d'examiner les implications pour l'éducation scolaire de la présence

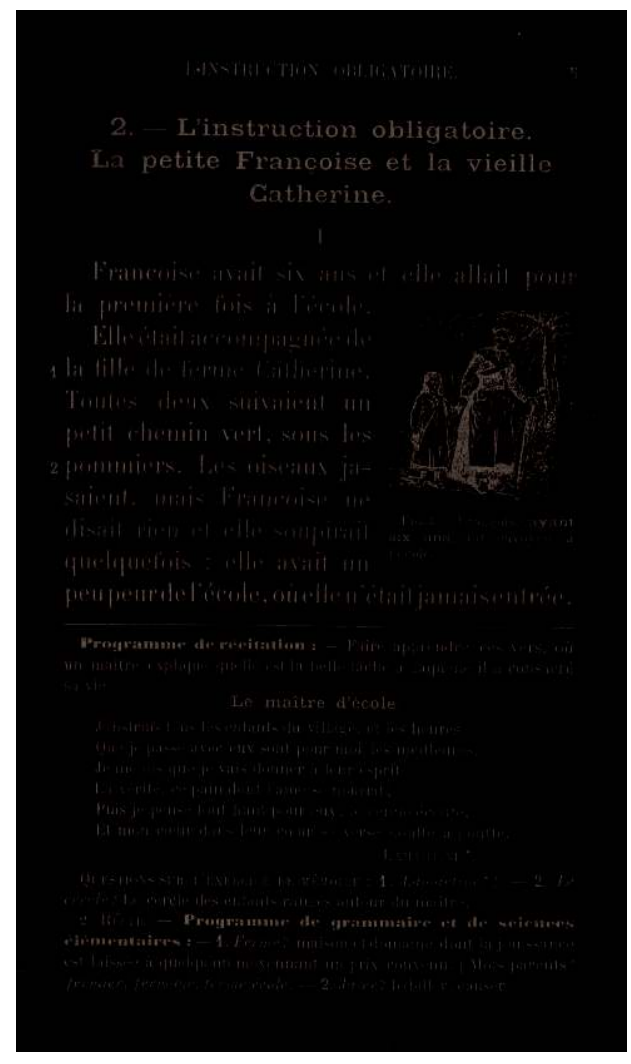
commune, au sein de l'école et de la classe, d'enfants ou d'adolescents appartenant à des cultures multiples. Cette présence de la diversité au sein de l'école est devenue commune à tous les systèmes éducatifs, du fait des brassages de populations liées à la globalisation. Il s'agira donc d'interroger la capacité de 
l'école et de l'enseignement scolaire à relever le défi de la diversité culturelle et d'indiquer les conditions à la fois pédagogiques et politiques dans lesquelles ce défi pourrait être relevé.

\section{L'Ecole de la République au sein d'un monde globalisé}

Dans une étude comparative menée en 2003 et portant sur cinq pays (Angleterre, France, Inde, Russie, États-Unis), Robin Alexander rappelait qu'« il n'est pas possible de séparer culture et pédagogie » et que "les pratiques pédagogiques ne sont pas neutres, que l'éducation est à mettre en rapport avec des idées et des manières de penser la société et que tout ce que nous voyons est ancré dans les histoires individuelles et collectives des participants, de leur éducation, de leur formation et des expériences qu'ils ont vécues, et du cadre plus large des politiques nationales, de l'histoire et de la culture » (Alexander, 2003, p. 17). S'agissant de la France, les principes et les valeurs qui continuent pour une bonne part à orienter les politiques éducatives trouvent leur origine dans la place dévolue à l'école par l'État républicain.

4 Dans un pays, où, à l'inverse de certains autres (l'Allemagne, l'Italie), l'État a préexisté à la nation et s'est voulu son principal édificateur, l'école a été pensée comme le bras pacifique de l'unité nationale. La spécificité de l'école française est d'avoir pris la forme historique d'une éducation nationale soucieuse d'intégrer dans les mêmes formes scolaires et, partant, dans le même moule politique, des populations d'origines, de langues, de religions, de conditions sociales ou de cultures différentes. L'école est ainsi investie d'un rôle central dans la production d'une unité politique et culturelle, autour de valeurs communes, autour d'une langue, d'une histoire et de savoirs communs. Cette fonction d'«institutrice de la nation", l'école ne peut l'exercer qu'en concevant sa mission comme une mission d'instruction publique, s'adressant à tous de la même façon et ignorant délibérément les différences et les particularités de tous ordres au profit de valeurs et de savoirs universels.

5 «En France, observe Robin Alexander comparant l'école française et l'école anglaise, l'école est un endroit où les enseignants viennent enseigner et où les élèves viennent apprendre. Mais en Angleterre, une école est - ou essaie d'être - bien plus que cela : un centre communautaire, ou même une véritable communauté en soi, un endroit où les enfants sont confrontés non seulement à des programmes, mais aussi à toute une gamme de valeurs sociales, un lieu unique de socialisation et un foyer de loyauté intense (...)» (Alexander, 2003, p.9). C'est à partir d'observations de cette sorte que Dubet, Duru-Bellat et Vérétout (2010a) proposent de définir des "styles éducatifs", en se fondant sur une approche qualitative du climat d'enseignement et du niveau de cohésion de la communauté scolaire. Un premier groupe, réunissant les pays de tradition anglo-saxonne (États-Unis exceptés) et l'ensemble des pays scandinaves, présentent le modèle de «la communauté démocratique ", caractérisé par la place accordée à la vie de l'établissement et à l'activité des élèves, par l'attention accordée à l'expérience et à l'épanouissement individuel des élèves comme à l'apprentissage de la vie collective : «L'école se présente comme une communauté d'expérience visant à produire des citoyens actifs et créatifs. » (Ibidem, p. 119) Un deuxième groupe, qui rassemble les pays de la Méditerranée, relève de «la communauté bienveillante», marquée par un climat détendu et des relations de 
confiance entre enseignants et élèves, par des conduite de participation et de solidarité, et globalement par une vie scolaire plus cohésive et plus égalitaire que ne le sont les sociétés des pays concernés. La France fait partie d'un troisième ensemble, où l'on trouve des pays de traditions éducatives bien différentes comme la Belgique, la Pologne, l'Allemagne ou la Hongrie, mais qui participent tous d'un modèle de « l'école du savoir »: les programmes et les enseignants y donnent la priorité à la transmission, à l'initiation aux disciplines, à la culture nationale, et malgré des climats de classe sensiblement différents (entre l'Allemagne et la France en particulier), les élèves ne s'y montrent pas particulièrement attachés à leur école ni confiants envers ce qu'elle peut leur apporter.

6 "L'école du savoir » définit par excellence l'école de la République. Celle-ci en effet ne se caractérise pas seulement par le rôle qui lui est assigné de former des citoyens et d'intégrer dans la nation, par une organisation et un fonctionnement centralisés valant pour l'ensemble du territoire (hiérarchies administratives, types d'établissements, programmes, formation des enseignants, etc.) : elle se signale en même temps par une certaine conception du savoir qui retentit fortement sur les modes pédagogiques et sur les relations entre enseignants et élèves. L'école républicaine postule de fait un modèle universaliste et rationaliste construit sur un principe d'homogénéité et d'unité touchant à la fois le savoir, l'élève et l'apprentissage.

7 Dans son principe, le savoir de l'école de la République est le même pour tous, et tous sont égaux devant l'école et le savoir, en vertu de la rigoureuse égalité que partagent les citoyens au titre de leur commune appartenance à la Nation une et indivisible. Tout le projet éducatif de l'école républicaine a visé à construire des langages et des appartenances communes, à former un être-français commun, en effaçant les différences: différences locales et régionales, différences linguistiques, différences religieuses et spirituelles. Cette construction idéologique constitue le fondement du volontarisme et du rationalisme scolaires républicains. Cela se traduit d'abord par une organisation "universelle» des programmes scolaires, les mêmes pour tous sur l'ensemble du territoire (y compris du territoire extra-métropolitain). Le même principe universaliste s'applique à la démarche de connaissance qui ne reconnaît qu'un seul mode : celui d'un formalisme hypothético-déductif devant opérer dans toutes les disciplines, les littéraires comme les scientifiques, et qui s'étend jusqu'aux « matières sensibles » des arts ou de l'éducation du corps. L'étude de la langue en particulier fait l'objet d'une approche formelle et autoréférentielle, dont Bernard Lahire $(1993$; 2008) a montré comment, au cours de l'histoire des pratiques scolaires, elle a généré des secteurs propres de savoir (la grammaire, l'orthographe) et s'est figée en exercices formels (la dictée, l'analyse grammaticale, la rédaction) qui n'ont plus de relation avec ce que l'on fait avec la langue (communiquer, dire le monde et soi-même, agir sur les autres et sur le monde, etc.) mais qui sont dans un rapport interne avec le code linguistique et discursif envisagé en luimême et pour lui-même.

8 Sous-jacent à ce modèle d'un savoir réifié et extérieur et de sa transmission selon une logique d'enseignement/acquisition toujours identique à elle-même, il y a la représentation de "l'élève » comme figure universelle et comme individu de droit, mais comme figure abstraite et comme individu privé en quelque sorte de lui-même et de tout ce qui le particularise: privé de ses localités et de ses appartenances, abstrait de son existence et de son individualité, et réduit aux seules assignations et qualifications que l'école lui confère, aux seules aptitudes qu'elle reconnaît en lui. Tel est le prix à payer de l'égalité formelle d'éducation que l'école de la République s'est ingéniée à construire et 
dans laquelle elle a cru voir la condition d'une justice scolaire propre à garantir une égalité au titre du mérite et des positions qu'il devait permettre d'acquérir dans la société (Duru-Bellat, 2009).

\section{L'Ecole française à l'épreuve du monde}

9 L'École française présente un certains nombres de caractères communs avec l'ensemble des systèmes éducatifs. Elle a également sa propre temporalité et ses propres réponses à des phénomènes propres à toutes les sociétés. Avec la démocratisation de l'enseignement (Merle, 2009) - d'aucuns diraient la « massification » de l'offre scolaire (Bautier et Rochex, 1998) - mise en œuvre à partir des années 1970, le monde de l'école, marqué par des valeurs et des significations comme l'égalité, l'universalité, le savoir objectivé, est confronté de plein fouet avec le monde social caractérisé quant à lui par la diversité, la pluralité, la particularité, les significations locales. À la bipartition sociale et à la dualité scolaire du primaire et du secondaire sur laquelle reposait l'école issue de la Troisième République succèdent «l'école pour tous » jusqu'à l'âge de 16 ans et l'entrée au lycée de jeunes qui, pour un certain nombre d'entre eux, n'y auraient pas eu accès dans les générations précédentes (Dubet, 1991). La relative homogénéité sociale du public scolaire de l'enseignement secondaire se trouve brisée, et avec elle, le consensus culturel entourant l'école, fait de représentations, de valeurs et d'attentes partagées par les parents comme par les élèves : « À partir du moment où la scolarisation longue devient la norme, on s'aperçoit que prévoir de nouvelles places ne suffit pas. Si les façons de faire, les références culturelles, les conduites attendues restent exactement ce qu'elles ont été, une part importante du nouveau public éprouve de telles difficultés qu'elle est rapidement éliminée comme inapte. » (Isambert-Jamati, 1990).

C'est ce que confirment les enquêtes nationales aussi bien qu'internationales. Si les derniers résultats publiés (OCDE, 2010) du programme PISA 2009 font apparaitre une nouvelle fois les résultats très moyens obtenus par les élèves français, ils mettent en évidence et accentuent par rapport aux enquêtes précédentes la dispersion et l'inégalité de ces résultats en fonction des différenciations socioculturelles. En particulier, la conjonction des facteurs liés au milieu familial (statut professionnel et niveau de formation des parents, nombre de livres à la maison, patrimoine culturel familial, indicateur de richesse, type de famille, ascendance autochtone ou allochtone, langue parlée en famille) apparaît déterminante pour les performances scolaires. La France est ainsi un des deux pays de l'OCDE (avec la Nouvelle-Zélande) où l'écart est le plus grand entre les élèves dont le statut économique, social et culturel des parents est le plus élevé et ceux dont le statut économique, social et culturel est faible. Alors qu'en moyenne, dans les pays de l'OCDE, cet écart, calculé selon l'indice PISA de statut économique, social et culturel, est de 38 points, il atteint plus de 50 points en France. Confirmant ces constats, le Rapport annuel des Inspections générales pour l'année 2009 s'interroge sur la pérennité de «la force intégratrice du projet scolaire de la République» et sur la «capacité de l'Éducation nationale d'assurer une réelle égalité des chances à tous » (Éducation nationale, 2009, p. 17).

11 Aux facteurs liés à l'origine et à la position sociale et culturelle s'ajoutent des formes de zonage socio-géographique qui, en concentrant sur des territoires délimités des populations présentant des caractéristiques socio-économiques semblables, ont également pour conséquence de ségréguer entre eux les établissements scolaires selon le 
territoire où ils se trouvent et le public scolaire qu'ils accueillent. Ces processus ségrégatifs associant lieu de résidence et lieu de scolarisation concernent plus particulièrement les centre-ville et les banlieues de toutes les villes françaises de quelque importance, avec le risque grandissant de voir s'installer une « école à plusieurs vitesses " clivant des espaces scolaires d'excellence et des espaces scolaires de relégation: «La question des ségrégations entretient (...) des relations étroites avec la problématique des inégalités scolaires. Elle implique en effet, pour les élèves concernés, un accès restreint au savoir, à l'orientation et aux diplômes. Elle se traduit par la scolarisation dans des espaces scolaires disqualifiés où se concentrent les inégalités: dégradation des équipements scolaires, enseignants jeunes et peu expérimentés, turn-over des équipes pédagogiques, perturbation des conditions de scolarisation et de l'ordre scolaire.» (Ben Ayed \& Poupeau, 2009, p. 6). L'assouplissement de la carte scolaire, intervenu en 2007 et censé favoriser la «diversité sociale " par la possibilité offerte aux élèves de choisir leur établissement, a au contraire renforcé les phénomènes de ségrégation sinon de ghettoïsation des espaces scolaires (Van Zanten et Obin, 2010).

La France et son école apparaissent ainsi comme « le paradis de la prédestination sociale » (Baudelot et Establet, 2009, p. 69) : si on la compare aux écoles des autres pays, l'école française est l'une des meilleures du monde pour une toute petite partie de ses élèves, qui sont très majoritairement issus des couches sociales les plus aisées au capital culturel et social le plus élevé; une des plus mauvaises pour une partie importante d'élèves de milieux culturels et socio-économiques défavorisés, qui s'y trouvent en difficulté ou en échec. Les difficultés de l'école française à accompagner de manière efficace des populations nouvelles de jeunes sont à la mesure des difficultés de la société française à assurer sa propre cohésion, à intégrer les populations les moins favorisées et, parmi elles en particulier, celles issues de l'immigration. Pour beaucoup de jeunes qui y font l'expérience répétée de la difficulté et de l'échec, l'école est le lieu d'une fracture entre l'expérience individuelle et la collectivité, un point de rupture ou de confirmation de rupture d'un lien social déjà fortement entamé dans les conditions habituelles de la vie sociale et politique (Giust-Desprairies, 2010). La crise de l'école française est aussi la crise du modèle de l'intégration "à la française " (Noiriel, 2006), dans un contexte, propre à tous les pays de l'OCDE, d'entrée dans le système scolaire des enfants nés de parents migrants.

\section{Pour une école de la diversité et une éducation du « sujet »}

Pour que l'école puisse (re)trouver sa fonction d'intégration à l'échelle de la Cité (ici différenciée de l'appartenance et de l'adhésion nationale), pour qu'elle puisse œuvrer à faire reconnaître un "droit de cité » (Balibar, 2002) à la diversité de tous ceux qu'elle accueille, il faut qu'une autre conception de l'éducation se fasse jour et qu'elle prenne le pas sur « l'universalisme communautaire » caractéristique de l'école républicaine. Il faut en particulier qu'émerge l'idée que l'objet premier de l'éducation consiste dans la formation et l'accomplissement de l'être individuel. Une telle finalité éducative suppose que soit pleinement reconnue la singularité individuelle et que soient pris en compte les multiples facteurs de différenciation qui la composent: différenciation psychologique, mais aussi linguistique, culturelle, sociale, etc. Cette autre conception n'en est pas moins 
politique, - elle constitue même un des fondements des démocraties modernes - mais elle considère d'une autre manière le rapport de l'individu et du social.

L'idée que chaque élève, que chaque personne en formation, que chaque "sujet » est un être singulier et que sa singularité ressortit à une diversité qui doit être reconnue en tant que telle est un préalable nécessaire et fondateur pour une éducation de la diversité, mais ce n'est cependant encore qu'un préalable. La problématisation d'une telle éducation suppose que l'objectif de formation de l'être individuel soit recontextualisé dans un cadre social et politique, elle suppose que soient tenues ensemble la finalité du monde commun et du vivre-ensemble et la reconnaissance de la différence individuelle et de la diversité culturelle. C'est une question très complexe à laquelle sont confrontés les systèmes éducatifs dans de nombreux pays. Cette question prend une acuité particulière dans les pays à configurations pluriethniques et multiculturelles ou dans ceux qui connaissent de forts mouvements migratoires entraînant la coprésence de populations culturellement plurielles : comment l'éducation et l'enseignement peuvent-ils œuvrer à l'édification d'un monde commun et d'un vivre-ensemble, tout en accordant leur place dans ce monde commun à des traditions et à des habitus culturels multiples ?

Car c'est bien de cet idéal-là qu'il s'agit: non de la juxtaposition forcément concurrentielle et conflictuelle de « communautés » renfermées chacune sur elles-mêmes et sur leurs spécificités, mais de la construction d'un monde commun où toutes les composantes culturelles puissent s'exprimer et être reconnues en elles-mêmes, mais aussi où chacune puisse entendre et reconnaître toutes les autres.

L'on mesure mieux alors toute la portée, mais aussi toute la difficulté d'une éducation de la diversité. La même question se pose à tous les enseignants d'un monde marqué par la pluralité. Comment tenir ensemble pédagogiquement le commun et le divers, l'un et le multiple, le même et l'autre? Une telle position implique chez le professeur qui enseigne comme chez l'élève qui apprend une démarche de compréhension particulière. En quoi consiste cette démarche ? À se décentrer d'un point de vue unique pour accéder à une pluralité de points de vue qui fasse droit à la diversité culturelle des comportements, des affects, des représentations, des valeurs. D'un point de vue psychologique et sociologique, cela suppose la capacité de sortir de modes de socialisation monoculturels et d'être ouvert à d'autres modes de socialisation et d'enculturation, pouvant d'ailleurs correspondre aussi bien à une altérité sociale ou sociologique qu'à une altérité culturelle au sens ethnologique du terme. Une telle démarche peut être qualifiée de compréhensive au double sens que donne l'étymologie et le sens commun : elle prend ensemble (cumprehendere) et elle entre dans les raisons de l'autre, dans ses modes de penser, d'agir, de sentir, de s'émouvoir, etc. Elle repose sur cette capacité profondément humaine à comprendre ce qui est humain, à appréhender les significations que l'autre (l'autre que moi, l'autre d'un autre milieu social, l'autre d'une autre culture, etc.) donne au monde, à saisir les motifs et les buts qu'il donne à son existence et à son action dans le monde ${ }^{1}$. Paul Ricoeur fait de cette capacité un des éléments de définition de l'être humain: «être homme, c'est être capable de transfert dans un autre centre de perspective » (Ricoeur, 1961, p. 451).

La traduction pédagogique d'une telle démarche compréhensive dans un contexte pluriculturel n'est pas des plus aisées et constitue très certainement un des enjeux mais aussi un des défis majeurs de l'éducation aujourd'hui. Sous le nom d'éducation interculturelle, d'éducation à la pluralité ou encore d'éducation à la citoyenneté, elle a pris diverses voies, selon les systèmes éducatifs et les modes de gouvernance politiques. 
Mais il est indéniable que le phénomène d'immigration, et la nécessité pour les politiques publiques de répondre au défi de l'intégration d'une population diversifiée, ont participé d'une «transnationalisation» de la question scolaire. Pour simplifier, il pourrait être commode de distinguer entre des démarches multiculturalistes et des démarches interculturalistes ${ }^{2}$. Les unes et les autres de ces démarches prennent acte de la diversité et de l'hétérogénéité des publics scolaires issus des multiples composantes ethniques, culturelles et sociales d'une population nationale, elles sont conscientes des inégalités et des discriminations de tous ordres - linguistiques, sociales, économiques - créées par les rapports de domination d'une culture «majoritaire» - qui est la culture du pouvoir et aussi celle de l'école - sur des cultures "minoritaires». Les unes et les autres de ces démarches visent à plus d'égalité et de justice, mais elles n'apportent pas les mêmes réponses aux situations et aux problèmes nés de cette confrontation des univers culturels.

Les démarches multiculturalistes enseignent la diversité dans un sens à la fois transitif et restrictif : elles mettent en place un enseignement ou en tout cas une information sur les cultures minoritaires ou d'origine, enseignement ou information destiné d'abord aux enfants issus de ces cultures "autres" et qui se traduit selon les cas par des apprentissages linguistiques, des informations historiques, géographiques, culturelles, etc. En prenant ainsi en compte les cultures d'origine, ces démarches visent un effet de reconnaissance et de réassurance, mais on peut se demander si, au bout du compte, leur objectif final, plus psychologique et stratégique que véritablement éducatif, n'est pas de faciliter l'intégration culturelle et sociale de publics considérés comme " hétérogènes ». L'expérience montre d'ailleurs que cet objectif n'est pas forcément atteint et que ce culturalisme pédagogique peut au contraire déboucher sur une exacerbation des différences identitaires et sur une ethnicisation des rapports entre les élèves, tout à fait contraires au but recherché.

Les démarches interculturalistes n'ont pas pour objet prioritairement d'enseigner les cultures, mais de développer des modes d'appropriation qui prennent en compte les caractéristiques culturelles des parties en présence : élèves, mais aussi enseignants, mais aussi institution scolaire, dans la mesure où l'école a elle-même une dimension culturelle, où elle est elle-même une culture au sens anthropologique du terme. On peut rappeler ici le mot de Jérôme Bruner disant qu'« apprendre à l'école, c'est apprendre la culture de l'école» (Bruner, 1996). Si l'on veut que l'enseignement soit autre chose qu'un processus d'adaptation et d'assimilation à cette "culture de l'école", et donc à la culture majoritaire, il faut concevoir une éducation qui inclut la pluralité comme une de ses dimensions constitutives et qui s'adresse à l'ensemble du public scolaire (AllemanGhionda, 2000).

Encore convient-il de bien s'entendre sur les mises en œuvre que cela implique : il ne s'agit pas prioritairement de transmettre, "de maître à élèves ", des contenus sur tel ou tel des univers culturels représentés dans la classe (même si de tels " moments " peuvent avoir leur raison d'être), il ne s'agit pas de faire s'exprimer pour soi et en soi les identités et les appartenances ethnoculturelles et les faire se confronter entre elles; il s'agit, dans le cadre des activités et des apprentissages communs à la classe, de créer les conditions pour que puissent se dire et puissent être travaillés ensemble les représentations, les langages, les modes de compréhension liées à la diversité des univers culturels (y compris celui de l'école en tant que tel) représentés dans la classe. C'est dire qu'une telle éducation à la pluralité implique une remise en cause des méthodes traditionnelles 
d'enseignement-apprentissage et qu'elle ne peut être mise en place que dans le cadre d'une pédagogie du dialogue et de la co-construction. C'est dire aussi toute la portée véritablement politique d'une éducation interculturelle qui se révèle en même temps éducation à la citoyenneté et à la démocratie.

\section{La pluralité, un défi commun à tous les systèmes éducatifs}

21 Défi pédagogique, la diversité ou la pluralité culturelle représente aussi pour chaque «apprenant» un défi biographique, défi qui ne peut être soutenu que dans un cadre collectif et qui a des implications directement politiques. Comment les enfants et les adolescents vivent-ils la confrontation avec la diversité culturelle ? Comment éprouventils leur propre différence culturelle? Quels sont les effets de la pluralité culturelle sur leurs représentations et leurs constructions biographiques, c'est-à-dire sur la façon dont ils se représentent eux-mêmes, dont ils construisent des images et des figures d'euxmêmes, ici dans le rapport à l'autre en tant qu' « autre culturel »? Deux voies de réflexion semblent ici pouvoir être suivies.

La première concerne l'école elle-même, en tant que l'école est en soi un univers culturel, est une culture; la deuxième concerne l'apprentissage de la diversité et conduit à s'interroger sur les conditions "politiques» dans lesquelles peut être mené le travail biographique que requiert un tel apprentissage de la part des élèves. La première observation à faire est que l'école en elle-même, ce que l'on fait à l'école et la manière dont on le fait, constitue pour tous les élèves, quelles que soient leurs origines et leurs appartenances, une expérience culturelle. L'expérience de l'école telle qu'elle est vécue par les enfants et les adolescents met à l'épreuve leur monde-de-vie originaire en confrontant celui-ci à l'univers de la culture scolaire (Delory-Momberger, 2003). La culture de l'école est caractérisée par la prédominance des signes et des discours sur l'expérience directe et par celle de l'intelligence abstraite sur les savoirs pratiques. Cette prédominance des signes et des discours est caractéristique à double titre de la culture scolaire: l'école n'est que très rarement le lieu d'une expérience directe du monde et d'une connaissance au contact du monde, le monde n'y est présent que sur le mode du discours-sur-le-monde. L'école privilégie d'autre part un rapport autoréférentiel au savoir : plus qu'à tout autre âge et plus que dans tout autre espace social, l'âge et l'espace de l'école sont ceux où l'on demande aux « apprenants » d'investir les savoirs pour euxmêmes, en dehors de toute finalité dans le réel. Pour toutes ces raisons brièvement indiquées, l'école constitue bien en elle-même une expérience de confrontation culturelle, plus ou moins forte, plus ou moins difficile selon l'origine et les appartenances des élèves, et qui réclame de leur part un travail d'ajustement, de négociation avec leur monde d'origine et avec les représentations qu'ils ont du savoir et de l'apprentissage. Cette confrontation entre la culture de l'école et les cultures originelles forme assurément un des espaces d'interculturalité sur lequel le maître ou le professeur peut intervenir pour comprendre la dimension «culturelle» des difficultés de l'enfant, reconnaître ses compétences et ses savoirs et l'aider à les transférer et à les utiliser dans de nouveaux contextes, selon de nouveaux modes (Ogay et al., 2002).

Le second aspect concerne les implications individuelles et collectives d'une éducation de la diversité. L'école n'est pas seulement un lieu où l'on apprend les « matières » de l'école, 
c'est aussi un lieu où l'on «vit ensemble » et où l'on apprend à vivre ensemble. Par les effets qu'elle entraîne, la présence dans les classes d'élèves issus de groupes culturels multiples constitue une dimension importante de ce vivre ensemble : diversité culturelle des représentations et des comportements, préjugés et stéréotypes dans les images que l'on se fait de l'«autre", tensions qui peuvent naître de revendications identitaires antagonistes, rapports de pouvoir implicites et explicites entre cultures dominantes et cultures dominées, dispositions inégales à la culture de l'école. La simple affirmation de principes de "respect de l'autre» et de "conduite citoyenne" ne peut suffire à transformer en harmonie universelle l'ethnocentrisme propre à chaque groupe culturel, ni d'ailleurs à faire oublier les réalités de l'histoire et de la société, à savoir le statut inégal des cultures et les rapports de domination qui ont existé ou qui existent encore entre elles.

Aussi n'est-il pas abusif de parler ici de défi à la fois dans les constructions biographiques et dans l'apprentissage de la « faculté de juger » : le déplacement et le dépassement de soi qu'implique l'ouverture à l'autre mettent véritablement à l'épreuve la centration de chacun sur soi-même et sur ses propres habitus culturels ; bousculant les assises et les réflexes culturels d'origine - qui constituent notre armature dans l'existence -, la décentration que requiert la reconnaissance de l'autre engage profondément les représentations que chacun a de soi-même et de son propre univers culturel ${ }^{3}$. Mais l'erreur serait de croire que, puisqu'il concerne chacun, ce défi biographique et cognitif puisse être relevé de façon solitaire. Un tel défi ne peut pas être une épreuve purement individuelle : il est lié à un projet collectif qui est celui de la constitution de la classe comme entité politique. La pluralité culturelle ne peut devenir une réalité et une pratique positives à l'intérieur de la classe que si celle-ci devient un espace commun d'activités et de projets, que si elle constitue pour chacun de ses acteurs - élèves et professeur - un monde commun à construire ensemble, que si la classe devient une figure de la Cité et de la démocratie citoyenne. C'est dans ce monde commun, vécu ensemble et construit ensemble, que chacun peut agir et être reconnu dans sa singularité et sa diversité, parce que cette singularité et cette diversité participent à une œuvre commune. C'est dans ce monde commun, qui littéralement "dénationalise » la question scolaire, que peuvent s'opérer cette appropriation biographique de la diversité et cet apprentissage d'une faculté de juger intégrant le point de vue de l'autre, dans la mesure où seul ce monde d'activités et de projets partagés permet à la figure de l'autre de trouver sa place et son sens dans les représentations et les constructions biographiques que chacun se donne de lui-même et de son action.

En ce sens, le projet d'une éducation à la diversité culturelle et les conditions politiques qu'il requiert pour pouvoir s'accomplir pourraient à bon droit s'inspirer des voies indiquées par Paulo Freire et de ses principes conjugués d'éducation dialogique et de transformation sociale: "Personne n'éduque autrui, personne ne s'éduque seul, les hommes s'éduquent ensemble, par l'intermédiaire du monde.» (2001, p. 62). 


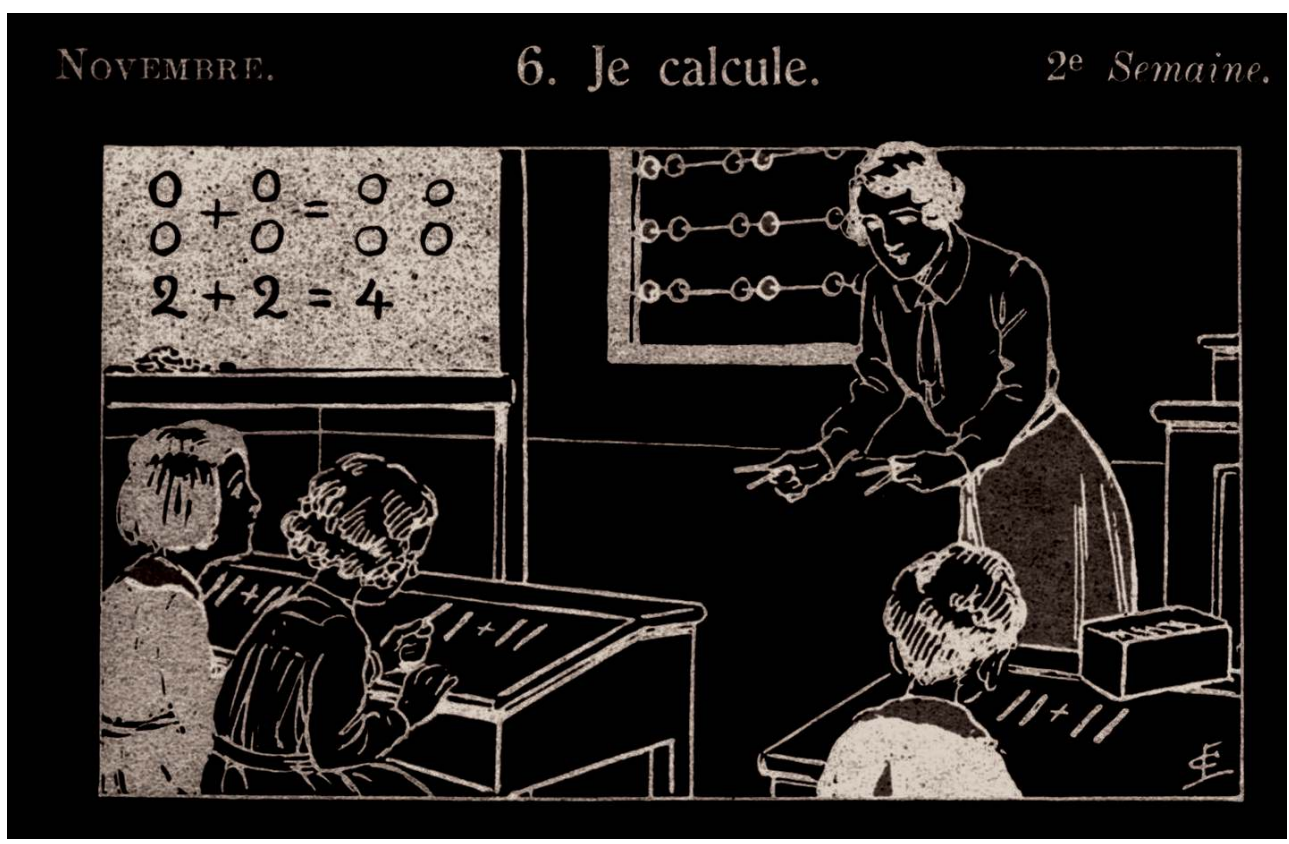

Vocabulaire, exercices d'observation et de langage : cours préparatoire classe de 17e des lycées et collèges (enfants de 6 à 7 ans). Lelu, Ad. ; Kubler, L. ; Voeltzel, L., Paris : Hatier, 1962, 9 édition. Illustrations en couleur V. Clérice. p. 16. Source : Cedrhe 578.

Van Zanten (Agnès). \& Obin (Jean-Pierre), La carte scolaire. Paris, PUF, 2010.

\section{BIBLIOGRAPHIE}

Abdallah-Pretceille (Martine), Vers une pédagogie interculturelle. Paris, Anthropos, 1996.

Abdallah-Pretceille (Martine), Former et éduquer en contexte hétérogène : pour un humanisme du divers , Paris, Anthropos, 2003.

Abdallah-Pretceille (Martine), L'éducation interculturelle, Paris, PUF, 2004.

Alexander (Robin). Pédagogie, culture et comparaison : visions et versions de l'école élémentaire. Revue française de pédagogie, vol. 142, 5-19, 2003.

Alleman-Ghionda (Cristina), « La pluralité, dimension sous-estimée, mais constitutive du curriculum de l'éducation générale ", in Raisons éducatives $\mathrm{n}^{\circ} 3$ : Pourquoi des approches interculturelles en sciences de l'éducation? (dir. Dasen P. R., Perregaux Ch.), 2000/1-2, Section des sciences de l'éducation de l'Université de Genève, p. 163-180, 2000.

Balibar (Etienne), Droit de cité. Paris, PUF « Quadrige », 2002.

Baudelot (Christian) et Establet (Roger), L'élitisme républicain. L'école française à l'épreuve des comparaisons internationales. Paris, Seuil, 2009.

Bautier (Elisabeth) et Rochex (Jean-Yves). L'expérience scolaire des nouveaux lycéens. Démocratisation ou massification? Paris, Armand Colin, 1998.

Ben Ayed (Choukri). et Poupeau (Franck) coord., École ségrégative, école reproductive. Actes de la recherche en sciences sociales, 180, 4-10, 2009.

Benn Michaels (Walter). La Diversité contre l'égalité. Paris, Raison d'agir, 2009. 
Bourdieu (Pierre) et Passeron, (Jean-Claude). La Reproduction. Éléments d'une théorie du système d'enseignement. Paris, Minuit, 1970.

Bruner (J.), L'éducation, entrée dans la culture. Les problèmes de l'école à la lumière de la psychologie culturelle, Paris, Retz, 1996.

Delory-Momberger (Christine), Biographie et éducation. Figures de l'individu-projet, Paris, Anthropos, 2003.

Dubet (François), Duru-Bellat, (M.), et Vérétout, (A.). Les sociétés et leur école. Emprise du diplôme et cohésion sociale. Paris, Seuil, 2010.

Dubet (François), Les Lycéens. Paris, Seuil, 1991.

Duru-Bellat (Martine), Le mérite contre la justice. Paris, Presses de Sciences Po, 2009.

Education Nationale, Rapport annuel des Inspections générales, 2009. http://

lesrapports.ladocumentationfrancaise.fr/BRP/104000483/0000.pdf

Freire (Paulo). Pédagogie des opprimés, Paris, La Découverte, 2001 (1969).

Frelat-Kahn (Brigitte). Réformes des institutions éducatives : un aveu d'impuissance ? Nouvelle revue de Psychosociologie, 9, 41-53, 2010.

Giust-Desprairies (Florence), Traitement de la diversité et crise du lien social dans l'école. Nouvelle revue de Psychosociologie, 9, 29-39, 2010.

Isambert-Jamati (Vivianne), Quelques rappels de l'émergence de l'échec scolaire comme problème social dans les milieux pédagogiques français. In E. Plaisance, L'échec scolaire : nouveaux débats, nouvelles approches. Paris, CNRS, 1989.

Lahire (Bernard), Culture écrite et inégalités scolaires. Sociologie de l'échec scolaire" à l'école élémentaire. Lyon : Presses universitaires de Lyon, 1993.

Lahire (Bernard), La raison scolaire : École et pratique d'écriture, entre savoir et pouvoir. Rennes : Presses universitaires de Rennes, 2008.

Merle (Pierre), La démocratisation de l'enseignement. Paris, La Découverte, 2009.

Noiriel (Gérard), Le Creuset français. Histoire de l'immigration XIXe - XXe siècle. Paris : Seuil, 2006.

OCDE, Résultats de PISA 2009 : Synthèse, 2010. http://www.pisa.oecd.org/

dataoecd/33/5/46624382.pdf

Ogay (Tania), Leanza (Yvan), Dasen (Pierre R), Changkakoti (Nilima), « Pluralité culturelle à

l'école : les apports de la psychologie interculturelle », VEI Enjeux, n 129, juin 2002.

Ricoeur (Paul), Civilisation universelle et cultures nationales. Esprit n¹0, octobre 1961.

Schütz (Alfred), Der sinnhafte Aufbau der sozialen Welt. Eine Einleitung in der verstehende Soziologie, Vienne, Springer Verlag 1960 (1934).

\section{NOTES}

1. Les fondements théoriques de l'approche compréhensive sont développés en particulier dans l'œuvre d'A. Schütz ([1934]1960). L'attitude compréhensive dont nous faisons mention relève du premier niveau du «comprendre» (verstehen) distingué par Schütz, celui de la « compréhension » en tant que forme d'expérience de la connaissance commune quotidienne. 
2. Cette distinction est clairement établie et développée dans les travaux de M. AbdallahPretceille $(1996 ; 2003 ; 2004)$.

3. «L'objectif d'une pédagogie interculturelle serait de saisir l'occasion offerte par l'évolution pluriculturelle de la société pour reconnaître la dimension culturelle, au sens anthropologique du terme, de toute éducation et d'introduire l'Autre, et plus précisément le rapport à l'Autre, dans l'apprentissage (...) La pédagogie interculturelle n'a pas pour objet d'enseigner les cultures, que ce soit la nôtre ou celle des autres, mais de redonner à tout apprentissage sa dimension culturelle. » M. Abadallah-Pretceille (1996, p. 158-159).

\section{RÉSUMÉS}

La difficulté particulière de l'école française à répondre à la diversité individuelle et collective des enfants et des adolescents qu'elle accueille ne peut être comprise que dans l'histoire contemporaine de l'institution scolaire en France, autrement dit dans sa fondation et sa tradition républicaines. Le projet éducatif de cette École a visé à former un être-français commun, en tentant d'effacer les différences, en privant le sujet de ses localités et de ses appartenances, abstrait de son existence et de son individualité, et en le réduisant aux seules qualifications et assignations que l'école lui conférait conformément aux impératifs de l'État-Nation. Avec la chute de l'Empire colonial, avec l'installation des migrants post-coloniaux en France, et la naissance de leurs enfants, induisant une hétérogénéisation des populations scolaires, avec la globalisation des savoirs numérisés, cette conception « communautaire » de l'éducation a vécu. Si chaque « sujet de l'éducation » est un être singulier et que sa singularité ressortit à une diversité, il s'agit de penser un vivre-ensemble respectueux des minorités culturelles, cultuelles et sociales et de poser les conditions scolaires (et politiques) d'un monde commun qui ne réduit pas les appartenances multiples à la seule appartenance nationale. Si le défi est biographique, l'enjeu en est politique.

The particular difficulty of the French school to meet the individual and collective diversity of children and adolescents it hosts can only be understood in the contemporary history of the educational institution in France, ie in its foundation and republican tradition. The educational project of the school aimed to form "à être-français", trying to erase differences, depriving the subject of its communities and its affiliations, abstract existence and individuality, and by reducing the unique skills and assignments that the school gave him in accordance with the requirements of the nation-state. With the fall of the colonial empire, with the installation of post-colonial migrants in France, and the birth of their children, resulting in a heterogeneous school populations, with the globalization of digitized knowledge, this design "community" of education experience. If each "about education" is a singular being and its singularity falls within a range, it is to think a respectful coexistence of cultural, worship and social minorities and ask school conditions (and political) a common world that does not reduce multiple attachments to one nationality. If the challenge is biographical, the issue is political. 
INDEX

Mots-clés : appartenances, biographisation, diversité, globalisation, nation

Keywords : affiliation, biographization, diversity, globalization

\section{AUTEUR}

CHRISTINE DELORY-MOMBERGER

Professeur en sciences de l'éducation à l'université Paris 13/Nord 